\title{
Trajectories of Appearance Concerns of South Korean Adolescents
}

\author{
Young-Min Yun', Soung Ho Jung ${ }^{2}$ \\ ${ }^{1}$ Professor, Department of Information Sociology, ERICA Campus of Hanyang University, Ansan; ${ }^{2}$ Doctoral Student, Department of Sociology, Graduate \\ School of Hanyang University, Seoul, Korea
}

Objectives: This paper examines how serious the appearance concerns of adolescents is in South Korean society by delving into the formation and changes of adolescents' appearance concerns. Methods: We conducted a secondary analysis of the data of multi-year tracing surveys which the National Youth Policy Institute opened to the public. The repeated Measures ANOVA, the paired t-test, and a chi-squared test were applied against the data. Results: It was found that about one out of ten adolescents experienced concerns that began as early as the upper grades of elementary school, reached its peak in middle school, and decreased afterwards. On the other hand, some of them faced enduring appearance concerns and seemed to suffer from it. One interesting finding is that adolescents once relieved from the concerns were free from it permanently. We also found that there were considerable differences between male and female adolescents in terms of the level of concerns they experienced, their peak periods, and other characteristics. Conclusions: Appearance concerns changes dynamically according to development of adolescence. Appearance concerns was less prevalent among adolescents than predicted, and it seemed considerably fluid. Our study not only confirms but also challenges some important findings of previous studies.

Key words: Appearance concerns, Lookism, Korea Youth Panel Survey, South Korean adolescents

\section{INTRODUCTION}

Lookism seems to have become a strong part of contemporary Korean culture. One commentator even described many Koreans as 'dying to look better' [1]. ${ }^{1)}$ Many people are unnecessarily anxious about their physical appearance and spend time and money in managing their appearance. For most of them, their appearance concerns originates not from their acquired abnormality but from their dissatisfaction with their own natural body.

What kind of psychology do adolescents experience within the culture of lookism? Adolescents, who are easily influenced by the dominant social culture, are presumed to be more subjected than any other social segments to the effects of such a 'lookism' culture. They are concerned about their perceived appearance more than what kind of person they are or may be in the future.

Research on these issues has been increasing, but we still need to know more to understand it and to do something about it. Macro-level causes that produce appearance concerns of people in South Korea are scarcely theorized or understood, but micro-level processes which make individual differences are also not well known. In fact, we are barely aware of the properties of appearance concerns itself. Is it serious enough to be considered a mental disorder or disease? Otherwise, is it just a minor anxiety which people temporarily experience during some period of life? Who are susceptible to appearance concerns? When does the obsession with appearance begin in one's life course? How does it change (or not change) once it is formed? These questions are still waiting to be an-

1) Plastic surgery, which may be an indicator of lookism, is very popular in South Korea [2]. According to an ISAPS global survey, approximately one in five women is cosmetically enhanced in the country, compared to about one in 20 women in the United States [3].

\section{Corresponding author: Young-Min Yun}

55 Hanyangdaehak-ro, Sangnok-gu, Ansan 15588, Korea

E-mail: youngmin@hanyang.ac.kr

Received: August 1, 2018 Revised: September 9, 2018 Accepted: September 12, 2018

No potential conflict of interest relevant to this article was reported.
How to cite this article:

Yun YM, Jung SH. Trajectories of appearance concerns of South Korean adolescents. J Health Info Stat 2018;43(4):245-254. Doi: https://doi.org/10.21032/jhis.2018.43.4.245

(c) It is identical to the Creative Commons Attribution Non-Commercial License (http://creativecommons.org/licenses/by-nc/4.0) whichpermit sunrestricted non-commercial use, distribution, and reproduction in any medium, provided the original work is properly cited.

(c) 2018 Journal of Health Informatics and Statistics 
swered to understanding the lookism phenomena [4].

Generally personal interest in appearance increases during adolescence. Adolescence is a period during which individuals experience physical development and secondary sex characteristics appear. Adolescents, who tend to be influenced by the mass media and their peer group, become interested in their appearance by comparing peers' bodies with themselves or by comparing celebrities' appearance, described through the mass media, with themselves [5-7]. The body image formed through that process becomes a part of the adolescent himself/herself, and if the cultural pressure on standardized appearance is great, many adolescents are believed to experience appearance concerns.

This paper will examine how serious the appearance concerns of adolescents is in South Korean society, where personal appearance is highly regarded. This is achieved by delving into the formation and changes of adolescents' appearance concerns. Here we focus on discovering the types of patterns the appearance concerns of adolescents have as a sociopsychological phenomenon. Hopefully our study contributes to fill the gap that the research on appearance concerns so far has.

\section{LITERATURE REVIEW AND ANALYTICAL FRAMEWORK}

Feminist scholar Rachel Hurst claimed that standardized beauty is being emphasized through Internet media, such as the mass media or social media, and that the surface is becoming more dominant than the inner side in current society [8]. In such a sociocultural environment, adolescents have, we assume, serious concerns about their appearance, which develops as appearance concerns.

Before discussing previous research, we would define appearance concerns, the key concept of our study. By appearance concerns we mean the psychological status of being dissatisfied with or ashamed of one's own appearance such as face, skin color, and body shape. If it becomes serious, it may cause timidity, discouragement, fear of social relationship, and lack of will-to-life, and may even develop as body dysmorphic disorder (BDD). We avoid using appearance stress, although the survey questions analyzed include the word 'stress', since the expression is often used in the context of facial or body alteration due to stress. We are reluctant to adopt the relatively well-known jargon appearance anxiety, which is somehow tied to Appearance Anxiety Inventory (AAI), devel- oped to diagnose BDD [9]. Appearance concerns has similar meaning as appearance anxiety but is relatively free from the specific connotation. ${ }^{2)}$

Research on appearance concerns so far can be divided into two large categories: its causes and its consequences. Self-esteem and physical condition (for example, obesity) have been pointed out as factors that cause appearance concerns. If the individual's self-esteem is high, he/she tends to have low concerns (or a positive body image), whereas if the self-esteem is low, he/she tends to have high concerns (or a negative body image) [10-15]. In addition, obese children tend to have lower self-esteem than normal-weight children [16].

Some reports conversely contend that if one has appearance concerns or a highly negative body image, his/her self-esteem becomes lower [1719], and that he/she is more likely to have serious depression [20,21]. Furthermore, adolescents' appearance concerns is known to be the third major category of concerns following those of academic performance and relations with their parents [22].

Appearance concerns also affects an adolescent's social behavior. Adolescents with high appearance concerns are likely to experience difficulties in forming close relationships with their peers at school [23], and psychological intimidation due to appearance can increase the possibility of adolescent aggression against his/her peers [24,25].

A few studies discovered gender difference in appearance concerns or body image. Female students showed greater sensitivity and higher concerns than male students regarding adolescent appearance [18,26-30].

Some research [31-34] reported that adolescents experienced changes in appearance concerns or body image as they grew old. Koh and Kim [32] reported that high school students, college students, and junior high students, in this order, had the greatest dissatisfaction with their body. Chung [31], who conducted a cross-sectional study of students from the ages 13 to 18 , published the result that one's satisfaction of own appearance continued to fall after the age of 13 but increased at the age of 17 and 18. In addition, Yang [33] revealed that 6th graders had lower satisfaction of body image than 5th graders. Recently using 2.5-year panel data of Australian adolescents (and their parents) Zimmer-Gembeck et al. [34] found that appearance anxiety grew in early adolescence from 10 to 15 years old. The pattern of linear growth was slightly more salient among girls than boys. They also found that physical maturation and teasing about appearance were associated with growth in appearance anxiety.

2) In fact, we follow the usage of Oxford Handbook of the Psychology of Appearance (2012). 
Although illuminating, these studies share a methodological limitation, except for Zimmer-Gembeck and her colleagues' work. Displaying changes according to growth period, these studies used cross-sectional data to compare the age groups. Age-group analysis of a cross-sectional survey only approximates effects of aging. It may be acceptable if longitudinal or paneled data is not available, but their findings are not free from the limitation that effect of aging cannot be separated from effect of period-change in one-time survey data [35].

Erikson's theory of personal development argues that adolescents are confused about self-identity and concerned over self-image [36]. The body image is formed, grows, and changes as a part of an individual's identity during adolescence. In order to be socially accepted and recognized, adolescents compare body images of peers and friends or a standardized body image presented by mass media with their own. Appearance concerns is an inevitable by-product that emerges during such a process of social comparisons. Within a culture where an individual's personality and inner-side beauty is well regarded, appearance concerns may be comparatively low. However, in a culture where a specific body image is idealized and where the surface dominates, adolescents seem to experience appearance concerns from early on and its seriousness is expected to be very high. Especially in a patriarchal society, it is assumed that the phenomenon appears more prominently among female children than male children.

Our research will focus on two questions which are important, we believe, to deepen understanding of appearance concerns: First, when does appearance concerns begin and how does it change (or not change)? Second, does the onset and subsequent changes differ according to gender?

\section{DATA AND METHOD}

\section{Data collection}

Our research analysed all the data of 4 th grade and 8th grade panels ${ }^{3)}$ of the Korea Youth Panel Survey (KYPS) conducted by the National Youth Policy Institute from 2003 to 2008. KYPS is one of a few tracing surveys of adolescents in South Korea. ${ }^{4}$ For the 4th grade panel, 2,844
Table 1. Gender composition of the samples to be analysed by panels

\begin{tabular}{lccccc}
\hline \multirow{2}{*}{ Variables } & \multicolumn{2}{c}{ 4th grade } & & \multicolumn{2}{c}{ 8th grade } \\
\cline { 2 - 3 } \cline { 5 - 6 } & $\mathrm{n}$ & $\%$ & & $\mathrm{n}$ & $\%$ \\
\hline Males & 1,194 & 52.7 & & 1,162 & 47.5 \\
Females & 1,073 & 47.3 & & 1,282 & 52.5 \\
Total & 2,267 & 100.0 & & 2,444 & 100.0
\end{tabular}

students have been interviewed every year for five years, from 2004 to 2008, and for the 8th grade panel, 3,449 students have been interviewed every year for six years, from 2003 to 2008 . Over $90 \%$ of the original subjects were kept for both samples.

Our analysis includes only the respondents who answered all the items regarding appearance concerns during the survey period: items 23-11, 23-12, 23-13, and 23-14 for the 4th grade panel; and items 49-12, 49-13, 49-14, and 49-15 for the 8th grade panels. ${ }^{5)}$ Accordingly, the subjects of our analysis are shown in Table 1.

\section{Analysis method}

First, we conducted a Repeated Measures ANOVA to find out the main effect and interaction effect of the factors according to the time of the test variable and the factor according to the sex. Additionally, a sphericity test was done to evaluate the suitability of the model, and when the sphericity was not satisfied, the $\varepsilon$ value earned by revising the degree of freedom was the criterion to decide the Huynh-Feldt value effect. Second, a paired t-test was conducted to figure out the significance of the difference in the score of the test variable by time. Third, progress, continuity, and other properties were analysed using panelled information to understand the characteristics of appearance concerns. Chi-squared test was applied to see statistical significance for cross-tables. Finally, All data were analysed with IBM SPSS 22.0 (IBM Co., Armonk, NY, USA) for Windows statistical package.

\section{DATA ANALYSIS}

\section{Trajectories of appearance concerns according to growth}

The Mauchly's sphericity test result of the 4 th grade panel $\left(\chi^{2}=155.7\right.$,

3) 4th and 8th grades are equivalent to 4th grade in elementary school and 2nd grade in junior high school respectively in South Korea.

4) A secondary analysis of KYPS belongs to categories of exemption from IRB Review. The KYPS is the study of existing data which is publicly available.

5) The questions used for analysis are common items for both the 4th grade and the 8th grade panels as follows:

(1) I get stressed because I weigh too much or too little. (4th grade $23-11$, 8th grade 49-12 question)

(2) I get stressed because I am too tall or too short. (4th grade $23-12$, 8th grade 49-13 question)

(3) I get stressed because of how I look. (4th grade 23-13, 8th grade 49-14 question)

(4) I get stressed because I cannot wear cool clothes. (4th grade 23-14, 8th grade 49-15 question) 
$p<0.05)$ did not guarantee sphericity. Therefore, the within-subject effects were re-examined based on the $\varepsilon$ value earned by adjusting the degree of freedom. The Huynh-Feldt $\varepsilon$ value was 0.966 , which is larger than 0.75 and close to 1 ; therefore, the Huynh-Feldt result was referred to. The probability value of the time according to the adjustment of the degree of freedom and the significant value of $\mathrm{F}$ of time ${ }^{*}$ sex were all under 0.001, which indicated that both effects were statistically significant. It is presumed that appearance concerns changes according to time, and the size of time effect depends on sex. The measurement of the betweensubject effects indicates that sex has a significant value of $\mathrm{F}$ being $p<0.001$ and has statistical significance, which suggests that there is a gender difference. The average of the appearance concerns seems to dif-

Table 2. Sex effects of appearance concerns on growth

\begin{tabular}{cclrrr}
\hline \multirow{2}{*}{ Variables } & Huynh-Feldt & $\begin{array}{r}\text { Type III } \\
\text { sum of } \\
\text { squares }\end{array}$ & \multicolumn{1}{c}{$d f$} & F \\
\hline 4th & Within- & Time & 481.5 & 3.86 & $233.1^{* * *}$ \\
grade & subjects & Time*sex & 23.8 & 3.86 & $11.5^{* * *}$ \\
& & Error & $4,678.0$ & $8,753.20$ & \\
& Between- & Intercept & $49,431.3$ & 1.00 & $28,214.3^{* * *}$ \\
& subjects & Sex & 316.2 & 1.00 & $180.5^{* * *}$ \\
8th & & Error & $3,968.3$ & $2,265.00$ & \\
grade & Within- & Time & 58.8 & 4.76 & $28.1^{* * *}$ \\
& subjects & Time*sex & 35.2 & 4.76 & $16.8^{* * *}$ \\
& & Error & $5,101.0$ & $11,615.20$ & \\
& Between- & Intercept & $96,942.4$ & 1.00 & $43,108.9^{* * * *}$ \\
& subjects & Sex & 418.2 & 1.00 & $190.4^{* * *}$ \\
& & Error & $5,491.5$ & $2,442.00$ & \\
\hline
\end{tabular}

Huynh-Feldt $\varepsilon$ 4th grade: 0.966 , 8th grade: 0.951 .

F-test $p$-value level: ${ }^{* * *} p<0.001$.

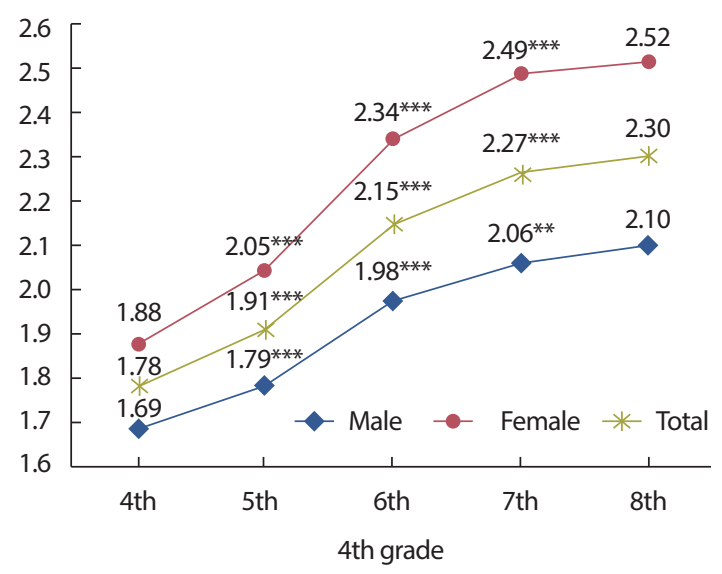

fer by sex (Table 2).

The result of Mauchly's sphericity test showed that the 8th grade panel did not guarantee sphericity either $\left(\chi^{2}=284.8, p<0.05\right)$. Therefore the within-subject effects were tested based on the $\varepsilon$ value earned by adjusting the degree of freedom. In the test results for the 8th grade panel, both the significant values of time and time* sex were under 0.001 , which shows that both effects were statistically significant. It is presumed that the transition of appearance concerns according to development period is significant and that the time effects differ according to sex. $p$-value $(<0.001)$ of $\mathrm{F}$ for the sex effect of between-subjects is so small that the gender difference may be considered statistically significant for this panel.

If we graphically represent the results (Figure 1), we can clearly see how adolescents' appearance concerns change as they grow older. The appearance concerns begins as early as 4 th grade. Judging by the fact that the average of the answer scores is low, it is likely to that only a small number of adolescents experience the concerns. We can, however, see that the average score continues to increase as the grade is higher. Particularly the average of female students gets higher quite rapidly. Results of the 4th grade panel indicate that appearance concerns continuously increases until the 8 th grade.

Looking at the results of the 4 th grade panel alongside the 8 th grade panel, there is a notable gap in the level of appearance concerns during the 8 th grade period. In the case of female students, the 8 th grade panel was 0.34 point higher than the 4 th grade panel. In the case of the male students, the 8 th grade panel was 0.21 point higher. This difference may be a testing effect, which is a phenomenon that occurs when the same

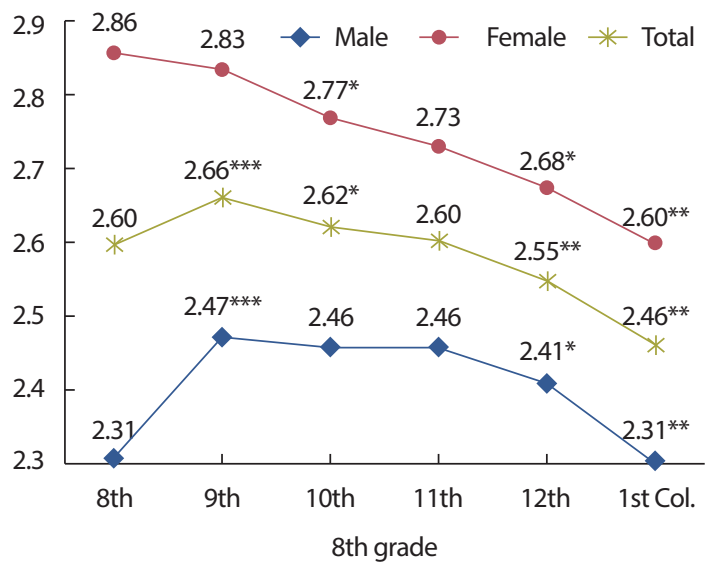

Figure 1. Changes in appearance concerns and difference test. 1st Col., 1st year of college. Paired t-test $p$-value level: ${ }^{*} p<0.05,{ }^{* *} p<0.01,{ }^{* * *} p<0.001$. 
measurement is repeated. ${ }^{6}$

First, this figure shows that students of upper grades of elementary school begin to experience appearance concerns. The low average of appearance concerns in the 4th grade starts to increase rapidly between the 5th grade and the 6th grade, and continues to increase significantly until the 7 th grade.

Second, when looking at the results of the 4th grade panel alongside the 8 th grade panel, we observe a remarkable difference between males and females in terms of the changes in appearance concerns. It is not surprising, however, that female students experience higher level of appearance concerns than male students, considering the patriarchal culture of the country.

Third, male and female respondents on average reach peak point in terms of appearance concerns in different periods of school years. For female students, appearance concerns reach its highest point during the 7 th grade or no later than the 8 th grade. On the other hand, for male students, it reaches its highest level in the 9th grade. This indicates that the appearance concerns of female students reaches its peak point one or two years earlier than male students. During the high-school period, both male and female appearance concerns reach their peak at around the 8 th grade and decrease until the end of the period.

Fourth, the changes in appearance concerns up to its peak are not linear. Once appearance concerns starts to form, it rapidly increases in its initial stage and slowly reaches the highest point to follow an $\mathrm{S}$ curve. After the peak period, appearance concerns display linearity with a low slope.

\section{Characteristics of appearance concerns during adolescence}

Among the physical elements of adolescents, perhaps the face is what changes the least. An adolescent's height may grow rapidly and his/her weight may either increase or decrease, but relatively speaking, his/her face does not change much. Some students have successful plastic surgery and may have less appearance concerns. However, let us put that aside and assume that physical face remains relatively the same. Now let us focus on the face and consider it to represent the appearance to simplify our analysis. In addition, to save space and for more focused analy-
Table 3. Percentage of respondents receiving face concerns

\begin{tabular}{lcccccc}
\hline Variables & 8th & 9th & 10th & 11th & 12th & $\begin{array}{c}\text { 1st year of } \\
\text { college }\end{array}$ \\
\hline Male & 182 & 192 & 161 & 157 & 157 & 111 \\
& $(15.66)$ & $(16.52)$ & $(13.86)$ & $(13.51)$ & $(13.51)$ & $(9.55)$ \\
Female & 388 & 320 & 275 & 263 & 265 & 222 \\
& $(30.27)$ & $(24.96)$ & $(21.45)$ & $(20.51)$ & $(20.67)$ & $(17.32)$ \\
Total & 570 & 512 & 436 & 420 & 422 & 333 \\
& $(23.32)$ & $(20.95)$ & $(17.84)$ & $(17.18)$ & $(17.27)$ & $(13.63)$ \\
\hline
\end{tabular}

Unit: $\mathrm{n}(\%)$.

sis, we will analyze only data from the 8 th grade panel below.

The concerns due to the face is apparently the highest during junior high, and the proportion of the respondents who feel stressed because of their face decreases noticeably during the senior-high period compared to the junior-high period (Table 3). The ratio of the face concerns appears to decrease even more after entering college. $23.32 \%$ of the respondents in the 8 th grade and $20.95 \%$ of the respondents in the 9 th grade answered that they were stressed due to their face. However, only $17-18 \%$ of senior-high students responded as having face concerns. In the first year of college, the ratio dropped to $13.63 \%$.

Looking into the female students alone, among the 8th graders about $30 \%$ answered that they had face concerns. However, the proportion decreased substantially by senior-high school and college. Male students' proportion did not fluctuate as much as that of female students, but their face concerns was the highest at $16.52 \%$ in the 9 th grade, and the ratio dropped greatly in senior-high school. In college, it decreased even more, with only about 1 out of 10 responding to have face concerns.

If a subject responded 'Yes' to the face-concerns question in the survey of a certain year but responded 'No' the next year, the face concerns of the respondent may be considered transient. On the contrary, if a respondent affirmed the question for two consecutive years, it may be considered somewhat enduring concerns. If a respondent affirmed the same question for three consecutive years of high school, that person had, we presume, quite enduring concerns due to his/her face during adolescence. Paneled data has made this kind of analysis possible.

The possibility of two consecutive years was 0.48 for 8 th grade-9th grade, 0.42 for 9 th grade-10th grade, 0.48 for 10th grade-11th grade, 0.50

6) For the 4th grade panel, appearance concerns that started from a low point increases as the survey is repeated and reaches the highest level in the 7th and the 8th grade. However, this graph does show that appearance concerns increases as grades go up but because the measured value in the 7th or the 8th grade reflects only a part of the test effect. On the other hand, the 8th grade panel measured students of the same grade, but since it is the first survey, the test effect cannot be applied. Therefore, presumably the test effect explains why survey results of the 4th grade panel and the 8 th grade panel show such a big difference. 
Table 4. Probability of face concerns for two consecutive years

\begin{tabular}{lccccc}
\hline Variables & 8th-9th & 9th-10th & 10th-11th & 11th-12th & 12th-1stC \\
\hline Face concerns & & & & & \\
$\quad$ Male & 0.46 & 0.39 & 0.39 & 0.41 & 0.33 \\
$\quad$ Female & 0.49 & 0.44 & 0.53 & 0.56 & 0.46 \\
$\quad$ Total & 0.48 & 0.42 & 0.48 & 0.50 & 0.41 \\
No face concerns & & & & & \\
$\quad$ Male & 0.66 & 0.67 & 0.69 & 0.73 & 0.77 \\
Female & 0.60 & 0.60 & 0.61 & 0.66 & 0.70 \\
Total & 0.64 & 0.64 & 0.66 & 0.70 & 0.74 \\
$\chi^{21}$ & $70.2^{* * *}$ & $40.8^{* * *}$ & $49.6^{* * *}$ & $48.9^{* * *}$ & $42.3^{* * * *}$ \\
\hline
\end{tabular}

1 stC, 1 st year of college.

${ }^{1} \chi^{2}$ is the result of $2 \times 2$ analysis of sex ${ }^{*}$ concerns $(d f=1.00)$.

$\chi^{2}$-test $p$-value level: ${ }^{* * *} p<0.001$.

for 11th grade-12th grade, and 0.41 for 12th grade-1st year of college (Table 4). In other words, $40-50 \%$ of respondents who answered that they had face concerns frequently or always affirmed the concerns in the next-year survey. This result implies that a sizable proportion of adolescents seems to experience relatively enduring appearance concerns.

In contrast, $50-60 \%$ of respondents who answered to have face concerns frequently or always at a survey in certain year said that they, from time to time, scarcely, or never felt the concerns in the next-year survey. From this result, we can conclude that the appearance concerns does not last long for the majority of adolescents. It seems, however, that the appearance concerns is still an enduring psychological status for not a few adolescents.

Interestingly, there was not much change in the continuity of appearance concerns as the respondents went from the 8th grade to the 9th grade, the 10th grade to the 11th grade, and the 11th grade to the 12th grade. However, when they go on from 9th grade to 10th grade, and 12th grade to 1st year of college, the continuity decreased remarkably. It requires more research to figure out whether this represents meaningful phenomena or just sampling variation.

In addition, respondents who displayed no appearance concerns are not likely to experience it next year. Once an individual is free from the appearance concerns, the possibility of regaining it is low (between 0.36 and 0.26 ). That possibility gradually decreases as one grows old. This implies that adolescents have somewhat stronger tolerance to appearance concerns as they mature.

If we expand our analysis to respondents who reported that they get stressed from time to time, the proportion of respondents who denied the appearance concerns in a survey of certain year, continue to deny the concerns completely, or get at most slightly stressed is over $90 \%$. This implies that once an adolescent gets over the appearance concerns, the possibility of regaining it in the future is extremely low. This may be considered a notable characteristic of appearance concerns during adolescence.

The possibility that female students experience face concerns for two consecutive years is consistently higher than for male students. There is a variation to some degree, but about half the female respondents who answered that they had face concerns affirmed the same question next year. Male students, on the other hand, although there was not much gender difference for junior-high students, had a considerable difference in the proportion during senior-high school. This difference is because the proportion of female students somewhat increased while that of male students decreased. During the first year of college, the proportion gap becomes slightly reduced. While $46 \%$ of the female students who affirmed the face concerns in the 12th grade responded 'Yes' in their 1st year of college, only $33 \%$ of the male students who affirmed it in 12th grade responded 'Yes' again.

There is also a difference between males and females in the proportion of not being stressed for two consecutive years, although it was not as large as in the proportion of being stressed for two consecutive years. The proportion of male students who answered that they did not get stressed for two consecutive years during junior-high school, senior-high school and in the first year of college was consistently higher than that of female students.

To put the above analysis together, we surmise that the face concerns (appearance concerns in broader sense) of adolescents may not be as serious as Hurst's surface theory implies. It conflicts with the widely-publicized trend dubbed 'plastic surgery fever.' To settle this discordance, let's take a closer look into the data.

Every year 10-20\% of respondents answered that they 'Frequently' or 'Always' get stressed due to their face. This number can hardly be said to be small; however, it is safe to say that the appearance concerns of adolescents is not great. If the face concerns of quite a few adolescents continues for a long time, then it might be an answer to the puzzle. Fortunately, the paneled data we have help us to understand the continuity of appearance concerns.

The data displays that $11.21 \%$ (274) of junior-high school respondents always experienced face concerns. It can be interpreted that many adolescents experienced enduring, presumably serious, appearance con- 
Table 5. Junior-high school students' face concerns

\begin{tabular}{|c|c|c|c|c|c|}
\hline \multirow[b]{2}{*}{ Variables } & \multicolumn{3}{|c|}{$\mathrm{n}(\%)$} & \multirow[b]{2}{*}{ Total } & \multirow{2}{*}{$\begin{array}{l}\chi^{2} \\
(d f)\end{array}$} \\
\hline & $\begin{array}{c}\text { Not } \\
\text { stressed }\end{array}$ & $\begin{array}{l}\text { Sometimes } \\
\text { stressed }\end{array}$ & Stressed & & \\
\hline \multicolumn{6}{|c|}{ 8th-9th Face concerns for two years } \\
\hline Male & $398(34.3)$ & $681(58.6)$ & $83(7.1)$ & $1,162(100.0)$ & \multirow{3}{*}{$\begin{array}{c}80.04^{* * *} \\
(2.00)\end{array}$} \\
\hline Female & $261(20.4)$ & $830(64.7)$ & $191(14.9)$ & $1,282(100.0)$ & \\
\hline Total & $659(27.0)$ & $1,511(61.8)$ & $274(11.2)$ & $2,444(100.0)$ & \\
\hline \multicolumn{6}{|c|}{ Face concerns throughout senior-high years } \\
\hline Male & $328(28.2)$ & $800(68.8)$ & $34(2.9)$ & $1,162(100.0)$ & \multirow{3}{*}{$\begin{array}{c}55.00^{* * *} \\
(2.00)\end{array}$} \\
\hline Female & $234(18.3)$ & 948 (73.9) & $100(7.8)$ & $1,282(100.0)$ & \\
\hline Total & $562(23.0)$ & $1,748(71.5)$ & $134(5.5)$ & $2,444(100.0)$ & \\
\hline
\end{tabular}

Unit: $\mathrm{n}(\%)$.

$\chi^{2}$-test $p$-value level: ${ }^{* * *} p<0.001$.

cerns. Out of these students, the number of respondents whose face concerns were not relieved after moving on to senior-high school is as many as 148. Sixty-four of these respondents even had face concerns during three years of high school. The number of respondents who had face concerns during three years of senior-high school was 134, so almost half of them are adolescents who had face concerns since junior high (Table 5).

Forty-four out of 64 students who had face concerns from the 8th grade until the 12th grade were not free from the concerns even after going on to college, while 44 adolescents were stressed due to their face from the 8 th grade until their first year of college. These students may be considered to suffer from serious face concerns, broadly appearance concerns, during their adolescence.

Thirty-six out of the 44 respondents who have answered that they frequently or always had face concerns since the 8 th grade to the first year of college were $82 \%$ female students and accounted for an overwhelmingly large proportion. It is not a surprising result in a society where there has been a strong tendency of judging women by their appearance. Undoubtedly female students get more stressed than male students. It does not mean, however, that most female students suffered from appearance concerns. Indeed, 38\% (105 respondents) of the 279 respondents who have never experienced face concerns were female respondents.

\section{CONCLUSION}

The goal of this paper is to look deeply into the characteristics of appearance concerns itself that have been overlooked by previous research.
Particularly, we try to find out changes over time and differences by sex.

To put all the results of our analysis together, we conclude that appearance concerns changes dynamically according to development of adolescence. Adolescents begin to have appearance concerns during the upper grades in elementary school and reach the peak point during junior high school. After the peak, the concerns are gradually relieved. This finding is similar to that reported by Chung [31] and Koh and Kim [32], but shows a slight difference in terms of period. Koh and Kim [32] reported that one's satisfaction of own body was the lowest during senior high school; meanwhile, we found that appearance concerns reached its highest point (implying one's satisfaction of own body was the lowest) during junior high school. Our finding did not accord with that of ZimmerGembeck and her colleagues [34]. Their data on Australian adolescents displayed relatively linear growth, with no peak point in appearance anxiety.

We found there were differences in appearance concerns between male and female, and this accorded with what Cho [18], Jang and Kang [26], Polce-Lynch et al. [27], Shim [28] and others had reported. In addition, not only do female students have more appearance concerns compared to males but they experience the concerns earlier in life than males. This seems to be due to the fact that secondary sexual characteristics appear earlier among female children who go through adolescence earlier, and that as Lim [37] claimed, women feel more social pressure regarding their appearance; similarly, as Slevin [29] argued, men focus on the functional aspect of the body while women focus on appearance.

According to our detailed analysis of the appearance concerns of adolescents and its progress, face concerns seems considerably fluid. It means that, in most cases, it is a temporary issue that comes and goes. The percentage of students who had concerns during all three years of senior high school was only 5.5\% and those who had appearance concerns since the 8 th grade to the first year of college is about $2 \%$. However, $10-20 \%$ of students have appearance concerns continuously every year, and if the proportion is expanded to students who sometimes get stressed, almost $50 \%$ experience concerns until they become adults.

Previous studies had focused mostly on the relationship of psychological variables during adolescence, and even if it examined the appearance itself like ours, it at most relied on one-time cross-sectional data. Thanks to KYPS, we were able to make use of invaluable paneled data and could complement previous studies effectively.

Our study has some limitations. We performed a secondary analysis 
of data collected for other purposes. Furthermore, we could not measure different but interesting tools of appearance psychology such as appearance anxiety inventory and body dysmorphic disorder, and thus could hardly explore correlates of the appearance concerns. In addition, the data analyzed for our study were collected ten years ago. Lookism in South Korea might have increased further, and values of parameters found in our study may be changed. Future research may address these issues.

We see that quite a few students have undoubtedly enduring appearance concerns and some of them may suffer from serious anxiety or concerns. However, according to our findings, we may conclude that majority of adolescents are psychologically healthier than are predicted by the critical social theories of lookism and implied by the journalistic description of lookism in South Korea.

\section{ORCID}

Young-Min Yun https://orcid.org/0000-0003-4914-5596

Soung Ho Jung https://orcid.org/0000-0002-3480-3691

\section{REFERENCES}

1. The Korea Times. 'Dying' to look better. Available at http://www.koreatimes.co.kr/www/news/opinon/2014/11/202_153377.html [accessed on January 31,2018$]$.

2. Jang HK. Why is plastic surgery so popular in South Korea?. KOREA EXPOSÉ. Available at https://www.koreaexpose.com/plastic-surgerypopular-south-korea-history/ [accessed on January 9, 2018].

3. International Society of Aesthetic Plastic Surgery. The international study on aesthetic/cosmetic procedures performed in 2016. International Society of Aesthetic Plastic Surgery, 2017.

4. Rumsey N, Harcourt D (eds.) The Oxford handbook of the psychology of appearance. Oxford: Oxford University Press, 2012.

5. Ricciardelli LA, Mellor D. Influence of peers. The Oxford handbook of the psychology of appearance; 2012, p. 253-272.

6. Shin KH. The difference of self-esteem and academic achievement according to children's body-esteem [dissertation]. Graduate School of the Korea National University of Education; Korea, 1996.

7. Smolak L. Appearance in childhood and adolescence. Oxford handbook of the psychology of appearance; 2012, p. 114-123.
8. Hurst RAJ. Surface imaginations. Montreal: McGill-Queen's University Press, 2015.

9. Mastro S, Zimmer-Gembeck MJ, Webb HJ, Farrell L, Waters A. Young adolescents' appearance anxiety and body dysmorphic symptoms: social problems, self-perceptions and comorbidities. J Obsessive Compuls Relat Disord 2016;8:50-55.

10. Do KH. The effects of children's self-esteem, eating attitude and school adjustment on body image. J Elem Educ 2008;21(3):111-125 (Korean).

11. Han MR. Relationships among the self-esteem, concerns of personal relationships and school adjustment [dissertation]. Yonsei University; Korea, 1996.

12. Kim JM, Yi SJ. Developmental changes in the effect of sociocultural factors towards appearance, body mass index and self-esteem on body image. J Korean Home Manage Assoc 2009;27(6):1-12 (Korean).

13. Lee JE, Auh S, Jung IK, Kim JH. The effects of body appearance satisfaction and self-esteem on the perceived obesity concerns in adolescence in Seoul area: a latent model. J Korean Home Econ Educ Assoc 2012;24(4):105-116 (Korean).

14. Moon KS. A study on the relationships of concerns level and self-conception in elementary school students [dissertation]. Yonsei University; Korea, 1993.

15. Yom YH, Lee KE. Factors affecting body image of undergraduate students. J Korean Acad Fundam Nurs 2011;18(4):452-462 (Korean).

16. Go MK. The physical satisfaction and self-respect according to the state of obesity elementary students [dissertation]. Graduate School of Education, Chosun University; Korea, 2004.

17. Baker L, Gringart E. Body image and self-esteem in older adulthood. Ageing Society 2009;29(6):977-995.

18. Cho YJ. The effects of appearance concerns on children and adolescents' self-esteem: mediating variables of sex-role identity and depression. J Korean Home Econ Assoc 2009;47(8):87-99 (Korean).

19. Park J, Choi T. The effect of body image on self-esteem in adolescents. Korean J Play Ther 2008;11(1):155-165 (Korean).

20. Shin NY. Associations among obesity, self-esteem, and depression in children [dissertation]. Graduate School of Seoul National University; Korea, 2006.

21. Woo M, Lee J. The mediating effect of body image and the moderating effect of demographic data on psychosocial problems of obese children. Korea J Counsel 2007;8(2):675-690 (Korean).

22. Song JS. A study on the comparison of concerns \& self-esteem be- 
tween an obesity child and a normal weight child [dissertation]. The Graduate School of Kyung Hee University of Education; Korea, 2011.

23. Lee AY. A study on the relationship between appearance complex, selfesteem, and school life adjustment for middle and high school students [dissertation]. The Graduate School of Ewha Womans University; Korea, 2007.

24. Nam JH. The effects of elementary students' appearance satisfaction on concerns coping behaviors and peer relationships [dissertation]. Graduate School of Myongii University; Korea, 2010.

25. Song SH. The mediating effect of negative self-concept on the relationship between adolescent's physical concerns and aggressive and depressive symptoms. J Sungkyul Psychol Counsel 2010;3:99-122 (Korean).

26. Jang MY, Kang GY. Convergent relationships among appearance satisfaction, self-esteem, and problem-solving ability of adolescent. J Korea Converge Soc 2017;8(4):79-87 (Korean).

27. Polce-Lynch M, Myers BJ, Kilmartin CT, Forssmann-Falck R, Kliewer W. Gender and age patterns in emotional expression, body image, and self-esteem: a qualitative analysis. Sex Roles 1998;38:1025-1048.

28. Shim WY. Mediation effect of active concerns-coping behavior in the relationship between appearance satisfaction and happiness of high school students. Korean J Teach Educ 2012;28(2):101-121 (Korean).

29. Slevin KF. If I had lots of money, I'd have a body makeover: managing the aging body. Soc Forces 2010;88(3):1003-1020.
30. Xu X, Mellor D, Kiehne M, Ricciardelli LA, McCabe MP, Xu Y. Body dissatisfaction, engagement in body change behaviors and sociocultural influences on body image among Chinese adolescents. Body Image 2009; $7(2): 156-164$.

31. Chung IY. Analysis of satisfaction level of body image in adolescency [dissertation]. Graduate School of the Korea National University of Education; Korea, 2000.

32. Koh AR, Kim YJ. The effects of egocentrism, self-consciousness, body cathexis on adolescence clothing behavior. J Korean Soc Cloth Text 1996;20(4):667-681 (Korean).

33. Yang SG. Analysis of satisfaction level of body image in elementary school age [dissertation]. Gongju National University of Education; Korea, 2003.

34. Zimmer-Gembeck MJ, Webb HJ, Farrell LJ, Waters AM. Girls' and boys' trajectories of appearance anxiety from age 10 to 15 years are associated with earlier maturation and appearance-related teasing. Dev Psychopathol 2018;30(1):337-350.

35. Babbie E. The practice of social research (13th ed.). International edition. Australia: Wadsworth, Cengage Learning, 2013.

36. Erikson EH. Identity, youth and crisis. New York: W.W. Norton \& Company, 1968.

37. Lim IS. The experience and intention of cosmetic surgery in the looksdiscriminatory society. J Korean Women's Stud 2004;20(1):95-122 (Korean). 


\section{국문초록}

\section{성장에 따른 외모 걱정의 추이: 한국 청소년의 사례를 중심으로}

\section{윤영민 $\cdot$ 정성호 ${ }^{2}$}

1한양대학교 에리카캠퍼스 정보사회학과 교수, ${ }^{2}$ 한양대학교 대학원 사회학과 박사과정

목적: 이 논문은 한국 청소년들의 외모 걱정이 언제 어떻게 형성되고 변화하는지를 추적하여 그것의 심각성 정도를 밝히고자 하였다. 방법: 한국청소년정책연구원이 공개한 다년간의 추적 조사 자료에 대한 이차분석이 시행되었다. 통계기법으로는 반복측정 ANOVA, 대 응표본 $\mathrm{t}$-검정 및 카이자승 검정이 적용되었다.

결과: 청소년들에 있어 외모에 대한 걱정은 초등학교 고학년에 시작되어 성장과 더불어 강화되다 중 2 나 중 3 을 지나면서 점차 약화되 는 것으로 판단된다. 일부 학생들은 청소년 시기 내내 외모에 대해 걱정하는 것으로 나타났지만, 고등학교나 대학에 진학한 후에는 청소 년들의 외모 걱정이 눈에 띄게 감소되었으며, 어느 시점에서 외모 걱정을 벗어난 청소년은 다시 외모 걱정에 빠질 가능성이 아주 적다는 사실도 발견되었다. 한편 외모 걱정에 성별 차이가 뚜렷이 나타났다. 평균적으로 여학생이 남학생보다 외모에 대해 더 걱정하며, 외모 걱 정이 남학생보다 1-2년 정도 더 일찍 정점에 도달하였다.

결론: 청소년의 외모 걱정은 성장과 더불어 역동적으로 변화한다. 외모에 대해 심각하게 걱정하는 청소년들이 적지 않지만, 일반적으로 추정되는 것보다는 청소년들의 외모 걱정은 상당히 유동적이며 다수의 청소년들이 외모 걱정에서 자유롭다고 판단된다.

주제어: 외모 걱정, 외모지상주의, 패널 연구, 한국 청소년 